\title{
TOTIUS AS TEOLOOG
}

Vakman-volksteoloog - Grondlegger van 'n Christelike Afrikatoekoms

"In theology there is, of course, no room for originality properly so called, for its whole materials are contained in the actual statements of God's word; and he is the greatest and best theologian who has most accurately apprehended the meaning of the statements of Scripture, - who, by comparing and combining them, has most fully brought out the whole mind of God on all the topics on which the Scriptures give us information".

W. Cunningham, The Reformers and the theology of the Reformation. Edinburgh 1866 , p. 296. (Aldus aangehaal voor in Polman, A.D.R. 1936. De Praedestinatieleer van Augustinus, Thomas van Aquino en Calvijn. Franeker).

\section{Oor- en onder- of onont wikkelde teologieë}

Die modeme teenstelling en probleem van sogenaamde ontwikkelde, dikwels oorontwikkelde, lande en volke teenoor ander wat onder- of onontwikkeld is, geld vandag tot 'n baie groot mate ook in die teologie. Basies moet ons dankbaar wees dat in die gelecrde teologic vandag soveel andag gegec word aan die Bybel as Woord van God, op welke wyse dan ook al, en dat tegelykertyd Bybelverkope orals in die wêreld toeneem en glo onlangs 'n hoogtepunt in Suidelike Afrika bereik het. Die suiwere en vrugbare gebruik van dic Bybel, vir beide geleerdes en ongeleerdes, 
word egter totaal getorpedeer deur oor- en onderontwikkeling aan die twee kante respektiewelik. By die meeste geleerde teoloë het ons helaas werklikwaar 'n moderne vorm van Areopagitiese praatjiesmakerye, elkeen wil met iets nuuts kom, met 'n eie, nuwe teologie, van revolusie, van hoop, ens., ad infinitum en dikwels ook ad absurdum. In hulle geleerde oorontwikkeling vlieg dié teoloe so hoog en so ver dat hulle nie net die Bybel kwytraak nie, maar ook die gewone volk. Laasgenoemde spartel dan maar op hulle eie aan, dikwels sonder kerklike instituut, alte dikwels ook sonder koers en krag in allerlei skakeringe van eensydige Biblisisme met ' $n$ veelvoud van spiritualistiese geesdrywerye.

Hierdie kloof en antitese moet oorbrug word as die Christendom sy taak en roeping in hierdie tyd en in hierdie wêreld godgehoorsaam wil volvoer. Elke mens, geleerd of ongeleerd, moet sy eie teologie hê en ontwikkel, dit wil sê die Christen moet nie net die eerste bede van die Onse Vader bid nie, met ander woorde net sit en bid in dié opsig nie, maar ook volhardend en ywerig hom inspan om die goud wat God hom gee in verhoring van sy gebed, ten volle te ontgin en in sy hele lewe te ontplooi. Hoe mooi en duidelik verklaar die Heidelbergse Kategismus nie hierdie eerste bede nie: „Gee ons eerstelik, dat ons u reg ken en $\mathrm{U}$ in al $u$ werke waarin $u$ almag, wysheid, goedheid, geregtigheid, barmhartigheid en waarheid helder skyn, mag heilig, roem en prys; dan ook dat ons ons hele lewe, ons gedagtes, woorde en werke so skik en rig dat u Naam om ons ontwil nie gelaster word nie, maar geëer en geprys word". Voordat mens met die Koninkryk van God doeltreffend en suiwer kan besig raak, moet jy eers sorg dat jy die Koning goed ken, soos Hy hom aan ons geopenbaar het op besondere wyse in die Bybel, en elke dag ook nog op 'n algemene wyse in die gang van die geskiedenis soos bely in artikel 2 van die Nederlandse Geloofsbelydenis. Met ander woorde dit is glad nie verniet dat Christus self die bede vir die koms van die Koninkryk tweede stel en nie eerste nie. 
In verband met hierdie eerste bede, moet ons nie sit en bid nie, maar bid en werk. Om God reg te ken, was nog altyd die eerste taak van die teologie, en dit is juis vandag seker die brandendste en mees verwaarloosde deel van die moderne teologieë. Dit is brandend noodsaaklik dat die Christendom hier tot bekering moet kom en hom weer opnuut behoorlik moet rekenskap gee van Wie en Wat sy God is, Wie se Koninkryk hy so ywerig, maar so verdeeld, met soveel antiteses onder mekaar, wil help realiseer, of soms somaar self, sonder God, wil realiseer.

Vir ons, Afrika-Christene, en miskien déúr ons vir die hele wêreld, gee Totius as geroepene van God in sy teologie die noodsaaklike en enigste basis. Hy is tegelyk vakmantcoloog wat sy geleerdste kollegas en opvolgers met eer te woord kan staan, maar net so ryklik volksteoloog, wat vir elke Christen, hetsy heeltemal ongeleerd of geleerd in alles behalwe die teologie, die nodige basis uit die Skrif gee om sy eie, persoonlike teologie, Godskennis, op te bou en uit te werk in die volle betekenis daarvan vir sy roepingsvervulling op alle lewensterreine.

Daarom noem ons hom grondlegger van 'n Christelike Afrikatockoms. In sy kleinheid en swakheid is hy die voorloper-nagverdrywer in Donker Afrika. Ons kan ook sê: die touleier-nagverdrywer van die „Boer van Afrika”, soos hy laasgenoemde besing in 1938 met die destydse simbolicse Ossewatrek en die daaropvolgende onthulling van die Voortrekkermonument.

Waar ons nou voortgaan om in hoofsaak hierdie tipering en waardering van 'Totius se teologie te motivecr, veronderstel ons dat die leser hiervan kennis geneem het van dr. V. d'Assonville se raak bockie Totius - Profeet van die Mooirivier, asook van sy artikel in Woord en Iaad (Februarie 1977) oor Totius as teoloog. Verder veronderstel ons 'n kennis van Totius se versamelde werke, al is dit net van die volledige inhoudsopgawes. 


\section{Vakman, Bybelkenner, Vegter - altyd in en met liefde}

Totius het nie sy persoonlike teologie op menslike wyse geërf nie, maar met sweet en swoeg verwerf. Hy is gedoop in die N.G. Kerk, maar vanweë sy vader se moeilikhede met die kerk, gaan studeer hy op Burgersdorp en lê hy belydenis van geloof af in die Gereformeerde Kerk, eers na baie ernstige geloofsworsteling. Die keuse word weer ter tafel gebring wanneer hy sy studies voltooi het en as proponent beroepbaar gestel word. Sy vader wil hê dat hy in die Kruiskerke hom moet beroepbaar stel, 'n oom wil hom in die Hervormde Kerk hê, maar tog handhaaf hy sy oorspronklike keuse van die Gereformeerde Kerk. Dit doen hy nie ligsinnig nie, maar met volle piëteit teenoor sy vader.

As hy in die oorlogstyd uiteindelik, na net soveel gewetensworsteling, as Kapenaar hom laat insweer as burger van Transvaal, en dan onder druk van vriende in Nederland gaan studeer, beland hy in Amsterdam aan die Vrije Universiteit in die hoogty van die Gereformeerde teologie, onder manne soos Kuyper, Bavinck, Woltjer, en andere, en word hy ook akademies-teologies ten volle bevestig in sy jongmanskeuse vir die Gereformeerde leer en Kerk. Hy voldoen met lof aan al die hoë vereistes aan hom gestel en kom in 1903 in die gehawende en oorlogverwoeste Transvaal aan as reeds bekende jong teoloog, doktor J.D. du Toit, van wie almal dadelik baie verwag, maar wat tog politiek-nasionaal deur sommige gewantrou is, onder andere vanweë sy vader se politiek. Hy oorwen hierdie wantroue egter baie gou en volkome, en in 1911 begin hy as 34-jarige sy lang loopbaan as professor in teologie te Potchefstroom.

In sy inougurele rede as professor, Die sestiende-eeuse profesie en die betekenis daarvan vir ons tyd kom dadelik een van die mees kenmerkende grondgedagtes van sy teologie na vore, naamlik die erkenning en volle handhawing van die amp van die gelowige. Die Kerk as liggaam van Christus behoort nie aan die geleerde teoloë, of selfs nie aan die predikante en kerkraad nie, 
maar is die volheid van uitverkorenes. Die gewone lidmaat is ook profeet, en die hoofdoel van die profesie was opwekking van die vrye lewe van die gees in die gemeente. Histories-wetenskaplik toon hy dit aan in die sestiende eeu. ,Allernaaste en allereerste moet dan die Woord van God weer aan die volk verkondig word. $\mathrm{Ja}$, 'die woord alleen gryp aan, deurdring, verander, bestuur, ontvlam, verkoel, hervorm die siele, al die siele...; die woord alleen knie siele'. As dit reeds waar is van die woord van mense, ook van die woord uit die afgrond, hoeveel te meer dan van die Woord van God". Hierin bely Totius allereers die allerintiemste band tussen alle gelowiges, geleerd of ongeleerd, besondere ampsdraer of gewoon in die amp van die gelowige, en tweede stel hy sy taak en roeping as teoloog en professor, naamlik nie alleen om predikante op te lei nie, maar om almal, die hele kerk volk, te bekwaam tot die suiwere profesie en volle uitlewing van die amp van gelowige. Elkeen, elke man en vrou moet steeds kom tot en groei in die ware Godskennis, en daaruit sy of haar lewensroeping vervul.

Is dit nie dié magtige orreltoon wat ons teenkom uit sy versamelde werke nie? My volk, God se volk, mag nie vergaan vanweë gebrek aan kennis nie! As vakman lê hy hier in sy intreerede die fondament van sy werk as volksteoloog by uitstek.

Die feit dat hy as vakman aanvanklik alleen professor was, en dus alle teologiese vakke moes doseer, en later, dat hy van tyd tot tyd ook weer feitlik alle vakke om die beuṛt gedoseer het, kan ons nou agterna miskien sien as bestiering van God, eers om hom voor te berei vir die Bybelvertaling, en later om ten volle die vrugte van so ' $n$ intieme kennis van die Bybel, woord vir woord en letter vir letter, vir alle vakke te benut. God het Totius gelei en ,gedwing" om steeds met die hele Bybel en die hele teologie besig te wees. In sy tyd het dit daarop neergekom dat hy steeds wetenskaplik die goddelike gesag van die Bybel moes, en met onderskeiding, kon verdedig en handhaaf. Destyds was dit teen die sogenaamde geleerde ongeloof met al sy skakeringe van evolusionisme. In beginsel gee dit vandag vir ons die fondament in 
die stryd teen allerlei geleerde areopagitiese teologieë en „ongeleerde" geesdrywerige verminking van God se besondere openbaring.

Sy hoofwerk in die 38 jaar, wat hy as vakman professor sou wees, bly bo alle twyfel sy Bybelvertaling, waarby met reg ook die Psalmberyming ingereken kan word. Sy gebalanseerde wetenskaplikheid, gedra deur sy intense liefde en agting van die wonder van God se openbaring in die Bybel as geheel, maak dan ook dat hy onbetwisbaar leier word onder die Bybelvertalers, wat almal goeie vakmanne was. Interessant om hierby te onthou, is dat hy reeds as student al in Nederland die hele Nuwe Testament in Grieks moes deurwerk en dat hy uiteindelik die hele Ou Testament nie minder as 112 keer deurgegaan het nie. Hy was dus voorwaar Bybelteoloog, wat alles wat God aan ons daarin geopenbaar het, sorgvuldig in die oorspronklike tale bestudeer het. Geen wonder dat al sy werk as teoloog, beide as vakman en as volksteoloog, hiervan deurdronge is en dat hy nooit in eensydigheid verval het nie. Deurgaans was hy Bybelteoloog soos deur Cunningham beskryf in die aanhaling bo-aan hierdie stuk - teoloog van die hele Bybel.

Dit dan nie in biblisistiese sin nie. Die konsekwensie van sy volle aanvaarding van die amp van die gelowige, ook in die leiding van die Heilige Gees deur die eeue heen van al die gelowiges saam as liggaam van Christus, trek hy ten volle deur in sy erkenning van en waardering van die belydenisskrifte van die kerk; ook in die dogmatiese, kerkregtelike en ander konklusies wat daaruit voortvloei. Dit sien ons baie duidelik in sy eerste produk as vakman, naamlik sy proefskrif: Het Methodisme. Die eerste deel daarvan is historics-geneties en handel respektiewelik oor die ceu, die vaders, die wording en die nuanseringe van die Metodisme; die tweede decl is sistematies-krities en gaan oor die idee, die metode, die leer en die organisasie van die Metodisme. Hierin gee hy vanuit Gereformeerde standpunt 'n skerp en volledige kritiek op die Metodisme, maar tog openbaar hy hierin nie die tradisioncle en berugte liefdelooshcid van tcoloë en teologieë onder me- 
kaar nie. Hy bly steeds 'n radikale vegter wat beslis 'n eie standpunt stel en handhaaf, maar sluit sy verhandeling af met die volgende woorde: „Aan die einde van my beskouinge gekom, wens ek ten slotte nog daarop te wys dat dit in hierdie dissertasie hoofsaaklik my bedoeling was om die Metodisme van Gereformeerde standpunt uiteen te sit en te beoordeel. Dit is egter nie gedoen om daarmee die groot werk van God wat deur middel van hierdie gecstelike beweging tot stand gekom het, te misken nie. Wesley en Whitefield was in die donker Deistiese eeu die instrumente in die hand van God om die Christendom uit 'n diepe slaap wakker te roep, en nog steeds klink sowel oor die Christelike erf as oor die velde van die heidendom hulle magtige woord na. Nie alleen Amerika dank sy teenswoordige Christendom grotendecls aan die werk wat deur hierdie manne begin is nie, maar hulle aksie het mede die stoot gegee aan die reusagtige sendingwerk van ons tyd. Ook het veral die Metodisme die oë geopen vir die node van 'n buitekerklike proletariaat, wat in godsdiens- en sedeloosheid versink het. En waar in die boesem van die Christelike kerk die droom van geestelike lewe in ortodoksisme en rasionalisme versand, daar is 'n Revival na Metodistiese trant dikwels die enigste redmiddel.

So lê dan ook hier die goeie en die kwaad deureengestrengel en bring dit ons tot stille aanbidding van Hom wat die manne verwek na sy welbehae en deur hulle swak en veelsins met sonde bevlekte pogings sy werk oplei na die voorgestelde doel". (Kursivering van my, DM).

Duidelik gaan dit hier nie vir Totius om die scge van sy teologie oor dié van ander manne nie, maar enkel alleen om die eer van God, om die ware Godskennis ook in die worsteling van teologiese en kerklike rigtinge.

Hier spreek duidelik by die vakmanteoloog die liefde tot God en sy waarheid, en vind ons daarom niks van die berugte en veel voorkomende haat van teoloë onderling nie. Dieselfde gees deurstraal ook al sy volksteologie, en ook sy optrede as vakman as 
getuie in die bekende Du Plessis-saak in Kaapstad in 1931, waar hy vir die N.G. Kerk as verweerder optree as getuie oor wat eintlik die suiwere Gereformeerde leer is. As ons hierdie getuie nis lees (Die Kerksaak tussen prof. J. du Plessis en die Ned. Ger. Kerk in Suid-Afrika, Kaapstad, Nasionale Pers, s.j.) dan word ons weer getref deur Totius se fyn teologiese onderskeidingsvermoë asook sy Bybelse gebalansecrdheid, wat verhoed dat hy vasgevang word in strikvrae met valse teenstellings. Ook hier belet sy liefde tot God en sy waarheid dat hy ooit haatlik en kleinlik word teenoor teenstanders. Duidelik kom dit ook tot openbaring as daar in die veertiger jare ook in die Gereformeerde Kerk konfessionele stryd ontstaan en in 1946 'n spesiale Sinodesitting gehou word in verband met die leer van prof. C.J.H. de Wet, wat uiteindelik toe die Gereformeerde Kerk bedank het. Ook hier moes Totius dikwels getuig oor die ware leer en die afdwalinge daarvan, maar steeds gebeur dit met taktvolle liefde.

Reeds in 1915 word op grond van sy verdienste as teoloog deur die Universiteit van Kaapstad die D.Div.-graad aan hom toegeken, en in die loop van die jare ontvang hy nie minder as sewe eredoktorsgrade nie, waarvan slegs dié van Potchefstroom kom van 'n inrigting wat uitgesproke die Gereformeerde geestesrigting toegedaan was. Sover my bekend, is Totius nooit van enige ongereformeerdheid beskuldig of maar selfs verdink nie, en nogtans tree hy só op dat hy sewe doktorsgrade ontvang van andersdenkende universiteite, plus bogenoemde cen van Kaapstad. Met ander woorde, hy slaag, deur die genade van God, daarin om streng-gereformeerd te bly, ook as vakman, en nogtans dic ander se agting te verdien en te behou.

3. Volksteoloog: Die lig van die Bybel oor die hele wêreld en alle lewensterreine

$\Lambda$ s ons die term volksteoloog gebruik ten opsigte van 'Totius moet ons baic duidelik daarby stel dat dit nic 'n geval was van populêrwetenskaplike brouwerk, of net dic popularisering van icmand anders se vakwerk nic. liintlik is dic onderskeiding in Totius 
se teologie tussen vakdeskundige werk en volkswerk nie heeltemal van pas nie. Al sy werk is 'n eenheid, gekenmerk deur die drie eienskappe wat dr. D'Assonville voorop noem, naamlik raak en fyn taalgebruik (oratio), heldere en verantwoorde denke (meditatio), plus pligsgetroue inspanning (tentatio), oftewel: welsprekendheid, denke en inspanning. Die kunstenaar-digter en nasionale volksman het ineengevloei met die egte, diepsinnige en hardwerkende teoloog, wat beide sy eie, intens-beleefde persoonlike Godskennis en sy oor-die-jare-versamelde en -opgeboude vakkundige Bybelteologie - op die regte wyse saamgegroei met sy uitgebreide kennis van en insig in konfessie, kerkgeskiedenis en kerkreg - nie gebruik het om vir homself naam te maak of homself in 'n ivoortoring op te sluit nie. As man van God was hy totaal tot beskikking van sy volk van God, profeet wat ander opbou in die ware profesie sodat hulle ook in die amp van die gelowige hulle plig ten volle kan doen. Hy was steeds ten volle getrou aan die bouprogram wat hy homself en die kerk ten taak gestel het in sy intreerede as professor.

Met bogenoemde talente en werkwyse het hy al die jare deur altyd nog gepreek, in die kerk, vir die volk. Net so het hy gereeld en volhardend sy bydrae in Die Kerkblad en elders gelewer. Geniaal kon hy in 'n kort artikel, of in 'n uitgebreide artikelreeks, die mees alledaagse en ook die moeilikste sake ontleed en bespreek by die lig van God se Woord - in verband met die geskiedenis van verlede en hede, sodat die vakteoloog dadelik kon sien dat hier 'n deskundige aan die woord is, terwyl die eenvoudigste lidmaat die kern van die saak kon begryp en vir homself kon toc-eien. Sy blik was oor die hele wêreld en hy het oog gehad vir alle lewensterreine. Soos hy die gewone lidmate met sy Psalmberyminge in staat gestel het om uit die hart in eie taal te sing, en só hulle aktiewe bydrae liturgies in die erediens te lewer, so het hy nie net sy studente nie, maar die hele kerkvolk opgebou en geleer om orals en altyd ter ere van God te werk en te stry. Hy het hulle gelecr om, getrou aan artikel 2 van die Nederlandse Geloofsbelydenis, in beide Skriftuur en natuur God raak te sien en te leer in al sy werke, in sy krag en majesteit en barmhartig- 
heid. Sy artikels en lesings het gegaan oor die subjek van die uitleg van die Ou Testament, oor die ewige lewe, oor die hel, oor Bybel en boerdery, oor die geskiedenis van die Afrikaanse kerke, oor die Christelike sedeleer, oor die liturgie van die kerk, oor die amp van die diakens, oor reënmakery, oor die atoombom, kommunisme, die opkomende Afrika, wêreldbedreiginge, Suid-Afrikaanse veelvolkigheid, oor ekonomiese sake, onderwyssake, volksbedreiginge, kommentaar oor 50 jaar se volksgeskiedenis, en so meer, en so meer. In alles was hy beslis en duidelik, maar steeds eg-profeties beskeie, hoegenaamd nie 'n beterweter of 'n goedkoop alwetende wyse nie.

Hy het Skrif en natuur in sy omvattende Godskennis, dit wil sê in sy teologie in allesomvat tende sin, as godgegewe eenheid beleef en beskryf. In sy teologiese klasse was dit geen dorre, abstrakte lesings nie, maar lewendige en vrugbare Bybelverklaring en, dikwels somaar meteen, konkrete toepassing. Interessantheidshalwe gee ek hier 'n paar voorbeelde, wat, ek vermoed, nergens neergeskryf is nie, maar wat ek persoonlik as student in die klas van hom kon ontvang.

Moses het 'n Egiptenaar doodgeslaan. As nasionaliste, sê Totius, kan ons dit heerlik geniet dat Moses so getrou is aan sy eie volk, maar tog bly hy juridies ' $n$ moordenaar wat die reg in eie hande geneem het. Boonop moes hy 'n baie sterk en knap bokser gewees het, want mens slaan nie so maklik 'n ander mens kaalvuis dood nie. Moses kon dus netsowel 'n misdadiger geword het; deur die genade van God het hy volksleier geword. Dit is net soos in die natuur: waar onkruid nie groei nie, plant jy verniet koring; 'n mens wat nie kan kwaad doen nie, kan ook dikwels nie goed doen nie. Waar baie onkruid uitgeroei word deur die genade van God, kan welige koring groei.

Abraham lieg en sê dat sy vrou sy suster is. Totius: ja, dit is nou dieselfde man wat by Moria 'n geloofsheld is en sy seun aan God offer. Hy is die vader van al die gelowiges, maar is slegter as 'n dronk niksnut, wat tog gewoonlik vir sy meisie sal baklei, en haar 
nie aan ander manne sal oorgee net terwille van sy eie veiligheid nie. Dit bewys maar net weer vir ons dat God se uitverkiesing uit louter genade geskied; uit hulleself is Abraham en sy mense eintlik nog slegter as ander, maar deur God se genade word hulle sy verbondsvolk.

Simson. Totius: as ons die geskiedenis van Simson in 'n gewoonmenslike geskiedenisboek sou lees, dan sal dit lyk of hy maar net 'n baie moedswillige kragreus was, wat ander manne se vroue vat en hulle, dic mannne, dan doodslaan as hulle beswaar maak. In die Bybel gegee, sien ons dit in 'n gans ander lig: Simson se sondes en swakhede word hoegenaamd nie ontken nie, maar as geroepene en uitverkorene van God in die heilsgeskiedenis, is hy in sy krag 'n tipe van die almagtige Christus. Net soos Christus later, is hy 'n gencraal sonder manskappe, wat alleen die stryd moet aandurf en volvoer, al word hy verraai en verloën, juis deur sy eie mense.

In pastoraal of kerkreg het hy die volgende staaltjie vertel: hy lei 'n kerkraad as voorsitter, daar ontstaan 'n geweldige debat en uiteindelik 'n skerp rusie tussen twee broeders. Hulle kan nie tot vrede of eenstemmigheid kom nie en die vergadering stap toe maar af van die twispunt en gaan aan met die ander werk. Aan die cinde van die vergadering vra hy een van die twee om met gebed af te sluit. Die man is nog so kwaad en ontsteld dat hy cintlik nie kan bid nie. Hy val toe maar van radeloosheid weg en bid die Onse Vader. Toe hy kom by ,vergewe ons ons skulde soos..." bly hy doodstil. Dic vergadering wag so 'n bietjie en maak toe hulle oc̈ oop, en sien dat die broeder sy hand uitsteek na die ander cen met wic hy getwis het en hoor hom toe sê: „Vergewe my, broeder..." Die ander huiwer effens, maar gee ook sy hand en vra ook: „Vergewe my..." Daarna het die eerste cen weer voortgegaan en dic Onse Vader verder voluit gebid. Daarmee was die lug volkome gesuiwer en dic vrede herstel. Hiermee het Totius atan ons geillustreer dat, vandag nog, net soos by die eerste kerklike vergadering in Jerusalem dit nie net ,ons" is nic, miar "die Ilcilige Ciees en ons..." (IIand. 15:28). Met ander woorde 
waar die menslike voorsitter en die menslike kerkraad nie meer raad weet met twisters nie, daar gryp die Heilige Gees direk in en stig volkome vrede deur 'n doodgewone versoek van die voorsitter aan iemand om die vergadering volgens roetine met gebed af te sluit.

\section{Touleier, voorloper van nagverdrywing uit Afrika}

'n Touleier is gewoonlik 'n klein mannetjie. Direk doen hy weinig; hy trek nie die wa soos die gespierde osse nie, dryf en jaag hulle ook nie aan soos die kundige drywer met sy fyn sweepkuns nie, en dra ook nie die vrag self soos die stewige wa nie, maar, veral by lelike en gevaarlike plekke is hy van deurslaggewende strategiese betekenis. Hy moet die hele trek sy koers laat hou en moet die moed hê om in die donker voor te loop en die grootste gevare te trotseer. Hy moet sy eie vrees en angs só oorwen dat dit nie deurstraal na die osse toe nie, sodat hulle nie in paniek omspring en die vrag omgooi nie.

Dït het Totius gedoen, as Afrikaanse volksman, as Suid-Afrikaner maar ook as teoloog. In sy kragvolle kleinheid was hy groot, nooit kleinlik nie; klein voor sy God, in eie oë klein voor sy medemens maar steeds in sy geloof en profetiese gehoorsaam. heid aan ,So sê die Here..." versiende en helder, onweerstaanbaar beslis en kragvol. In sy verhouding met sy medemens het hy nooit hiërargies op 'n eie gemaakte troon geklim nie, maar steeds presbiteriaal langs hom gaan staan, op die basis van die amp van die gelowige, waarin almal gelyk, hoewel nie eners is nie. (Self het ek as gewone student ondervind dat hy in 'n besige straat by my verby stap sonder om te merk dat ek hom groet; 'n endjie verder dring dit tot hom deur dat 'n medemens hom gegroet het en daar spring hý, die besige en haastige ouer man, werklikwaar om en haal die jongeling weer in en vra verskoning dat hy hom so pas nie gegroet het nie. Dit was ook geen oordrewe nederigheid nie, dié soort waarop party sogenaamde nederige mense naderhand hoogmoedig is. Nee, dit was net eenvoudig die konsekwente en eerlike toepassing van die boodskap van sy inougurele rede 
as professor, hierbo behandel.)

Mense wat niks weet van 'n ossewa en toulei in Afrika nie, sal laasgenoemde werk hecltemal misken en geringskat, en so die touleier as ' $n$ amusante tierlantyntjie beskou, en dan met die ou grappie kom: hoe kan so 'n klein mannetjic soveel sterk osse en so 'n swaar vrag aansleep. Dit is presies wat diegene doen wat Totius, op allerlei terreine, net in sy kleinheid raaksien. Hulle kyk na die gestalte van dic man en sien nie sy grootste en deurslaggewende taak deur God aan hom in nic-bepaalde omstandighede gegec met 'n bepaalde doel en roeping, naamlik die raaksien en uitken van die Boer van Afrika as nagverdrywer in die Donker Kontinent, en die lê van die noodsaaklike geestelike fondamente waarop voortgebou moet word, nie net deur die Boer nie, maar ook deur die Brit en al die ander volke en nasies.

Bloot as mens, en ook as toulcier, sien hy die angsvolle nagdonkerte van Afrika baic duidelik raak en beskryf hy dit, soos ons mecstal vandag dit ook sien, as bloot 'n opvolging van heerskappy, cers van dic F.ngelsman, dan van die Boer en uiteindelik van die Swartes. (,Kalferlied" in Uit Donker Afrika). Eg-menslik is hy in nog meer gedigte en uitsprake baie pessimisties, maar ielkens breek dic lig deur as hy kinderlik-gelowig die finale oorw!n ning van dic kvangelic sien - byvoorbecld in die gedig ,Dias by die Cabo Tormentoso" en ook in "Dic Trek van Boerewaens". Dic Boer sal dan oorwin, maar nie as alleenhecrser nic, maar uitcinclelik weer as Christenprolect, dienskneg van dic Allerhoogste, maar ook dienaar van al dic mense van Afrika. Hierdie heel laaste gedagte het Totius, sover ek weet, nie eksplisict gesê nie, maar dit is implisict ingesluit in sy profesic van lig oor Afrika. Iets hiervan sien ons al deurskemer as Totius, die klipharde Re. publikein en Afrikanernasionalis, eredoktorsgrade ontvang van dic Kingelssprekende universiteite van Witwatersrand en Kaapstid; miskien is daar ook 'n heenduiding hicrop in sy digterlike beskrywing wan die Bantoctaal (ook in Uit Donker Afrika), en in sy arrikel oor ,Dic sluimerende Afrika” (Die Kerkblad, 19 Junic 1942). 
As teoloog was Totius nie oorspronklik nie, nie in die moderne slegte sin van die woord soos in die begin van hierdie artikel aangedui nie, ook nie in die goeie sin soos Augustinus en Cal. vyn byvoorbeeld, wat albei nuwe waarhede uit die Bybel vir die Kerk geformuleer het. Totius was teoloog by uitstek in die sin van uitbring van "the whole mind of God on all the topics on which to Scriptures give us information". (Cunningham, soos aan die begin aangehaal). Hy het in Amsterdam gestudeer in die hoogty van die Gereformeerde teologie, en die erfenis van die Hervorming volledig na Suid-Afrika gebring - die teologiese erfenis soos gebou op die konfessionele erfenis, wat reeds deur Van Riebeeck in 1652 hierheen gebring is. (Vergelyk sy rede by die Van Riebeeckfees te Potchefstroom, 1952.)

Hy het dit nie op hoorsê aanvaar en verkondig nie, maar self weer beleef en weer vir die kerkvolk vertolk en toegepas, hier en nou, in verband met die titaniese opbouwerk wat veral die Afrikaner moes doen in die eerste helfte van die twintigste eeu. Die fatale kloof tussen oorontwikkclde teoloë en teologicë en, aan die ander kant, onder- of onontwikkelde teologie, van die volk is deur hom persoonlik oorbrug. Hy het die eenheid gehandhaaf, ook deur sy gedigte en ten sterkste laat funksioneer - juis in sy teologie. Daarom was hy as man met nege doktorsgrade stecds maar net dic gelicfde Totius of Doktertjic, soos so raak deur dr. D'Assonville beskrywe.

As ons nou waaragtig vanaf hicrdic T'otiusjaar vir dic laaste kwart van die twintigste ecu en verder, wil voortbou op die nagverdrywingswerk in Donker Alrika, moct ons duidelik sien wat die fondamente was waarop hy gebou het en helder en sterk daarop voortbou.

Daar is eintlik net een fondament, naamlik suiwere Godskennis vir ieder en elk vanuit die Bybel as Woord van God. Waar Totius en sy geesgenote in hulle tyd moes veg, dag en nag, vir die reg om die Bybel ook as fondament van hulle wetenskap te gebruik, daar belect ons die wonderwerk van God vandag dat die Bybel as so- 
danig deur feitlik almal erken word, al is dit nog op verskillende maniere. Waar die Potchefstroomse Universiteitskollege baie jare in gevaar gestaan het om gesluit te word, onder andere vanwee sogenaamde onwetenskaplikheid, is dit vandag wetlik erken as die PU vir CHO, en het die sogenaamde ideaal van neutrale onderwys heeltemal op die agtergrond geraak.

Nou staan ons voor die gevaar wat ons heel aan die begin genoem het, naamlik torpedering van die vrugbare gebruik van die Bybel deur die kloof tussen en antitese van oor-en onderontwikkelde teologie. Om die kloof te oorbrug en die eenheid tussen geleerdes en volk te handhaaf, nie net in die teologie nie, het Totius in sy teologie, teoreties en prakties, die noodsaaklike grondbeginsel gestel naamlik: die volle erkenning en daadwerklike handhawing van die amp van die gewone gelowige. Waar die wêreld daarbuite dweep met een-man-een-stem, het ons hierin die erkenning van elke gelowige as volledige mondige mens voor God. Een van die Amerikaanse presidente het gesê: „Men must be ruled by God, or by tyrants". Dit is vandag ook Afrika se keuse. Hoe meer mondige manne en vroue van God daar in elke volk is, des te sekerder is dit dat die volk hom deur God sal laat regeer; hoe meer sodanige volke in Afrika, hoe gouer sal die donker wyk en die lig oor die kontinent uitbreek. Die mondige gelowige lewe vanuit sy eie teologie, sy persoonlike Godskennis, en put dit uit die Woord van God onder leiding van die Heilige Gees. Egter nie net uit die Bybel, die besondere openbaring van God nie, maar ook uit die openbaring van God in die natuur, die daelikse gang van die geskiedenis, die bestiering van God - soos onder andere in die grondwet van die R.S.A. erken. Teologies beteken dit die erkenning en handhawing van artikel 2 van die Nederlandse Geloofsbelydenis, die tweede grondleggende beginsel deur Totius in sy teologie erken en gehandhaaf. Dit belet die geleerde teoloog om beide Bybel en volk kwyt te raak en die volk om op loop te gaan met een of ander vorm van geesdrywery.

Dit het God teologies aan Afrika gegee, deur Totius: met die Bybel, Woord van God, as primêre fondament van alles. Daarby, in 
die gebruik daarvan veral die twee grondbeginsels wat in die Konfessie bely word, naamlik: dic beklemtoning van die amp van die gelowige en die erkenning van die bestier en openbaring van God in die geskiedenis. Altwee hierdie grondbeginsels kom uit die Bybel, maar word so dikwels nie raak gelecs nie, of miskien wel raak gelees, maar nooit toegepas nie. Die konsekwente tocpassing van hierdie twee grondleggende beginsels sal ook die kloof tussen volke, nasies en groepc oorbrug, sonder om die een in die ander op te los; ook wanneer twee volke, afgesien van ander verskille, die een oor-en die ander onontwikkeld is op die gebied van dic Christelike godsdiens en teologic.

Op die fondament moet nou in ons tyd voortgebou word. Dit kan ook 'n trek met gedagtes genoem word (soos dr. D'Assonville Totius aanhaal op p. 56 van sy bockic). Hicrby trek dic Boer van Afrika voor en Totius is sy toulcier, ook in die teologic. Hierdie teologie vir Afrika mag dan nie ditse of datse of watse of wie se teologie, ook nie wit of swart teologic wees nic, maar 'n waaragtige Bybelteologic wat vir almal, 'n ieder 'n 'n clk, ware en vrugbarc Godskennis bring.

D.C.S. van der Merwe 